\title{
The NEC and the culture of the industry: some early findings regarding possible sources of resistance to change. ${ }^{1}$
}

\author{
John Rooke and David Seymour
}

Published as:

Rooke, J. \& Seymour, D. (1995) 'The NEC and the Culture of the Industry: Some Early Findings Regarding Possible Sources of Resistance to Change,' Engineering, Construction and Architectural Management, 2(4):287-307.

\begin{abstract}
.
The paper describes some current research into the impact of the New Engineering Contract (NEC) on the culture of the industry. The intention is to explain the purpose of this research, describe the methodology we are using and report on some early findings. In the early sections, we outline the thinking behind the research and some of the difficulties involved. We briefly consider the limitations of a conventional approach and compare it with an outline of our own. We then look at the analysis of data, with reference to some findings of this and a previous study. In doing so, we focus on some cultural patterns which may be resistant to the changes the NEC is intended to promote. We go on to discuss some of the ways in which culture is transmitted between individuals, since, if the NEC is to be successful, it will involve changes in these patterns. In the final section, we discuss some implications for the future of the NEC.
\end{abstract}

Keywords Construction Industry, New Engineering Contract, Contract, Culture, Methodology, Occupations, Change.

\section{The Purpose of the Research.}

Since the publication of Peters' and Waterman's book In Search of Excellence (1982), there has been much interest in culture as a kind of under-used organisational resource. They persuasively argued that achieving all the desired aims of organisational activity profitability, competitiveness, long term viability and so on - had more to do with the underlying attitudes, beliefs and values of people and less to do with the formal structures and consciously formulated procedures which had hitherto largely been the focus of interest for theorists and practitioners.

While the importance of the informal undercurrents of organisation had been recognised at least since Mayo (1945), Peters' and Waterman's explicit rejection of what they saw as the stultifying effects of the over-elaboration and 'scientification' of the formal aspects of organisation, seemed to strike a deep chord in the American, and more recently, the British psyche. It was about getting back to basics, regaining a sense of contact with what was being produced and with those for whom it was produced; freeing the desire of people to do a good, honest job and enjoying the sense of personal growth that this allowed.

1 This research is funded by the EPSRC, as part of a joint project with the University of Bath. 
A similar sense of the need to get back to basics and break away from the proliferation of contractual forms and over-elaborate contractual provisions, seems to have inspired the New Engineering Contract. Its originators' stated aim is to provide a coherent set of documents that is flexible, readily understandable to the users and therefore free from legal jargon, providing a framework that would facilitate the assumed aim of construction practitioners to work more collaboratively and efficiently (ICE 1993).

Many believe that relationships in the construction process are now dominated by suspicion, mistrust and cynicism; that there has developed a culture of confrontation and conflict where too much of people's attention and energies are directed towards defending themselves against the opportunism and unreasonableness that they see in others, rather than at finding ways of collaborating more effectively. The NEC is intended, to provide a framework which will encourage collaboration and planning.

Our research has three purposes: first, to investigate present attitudes, habits, and assumptions; second, to establish how these are being affected by the use of this new contract; third, to explore the methods by which cultural patterns are spread. Underlying these purposes is the assumption that culture in its nature is constantly being created and that for those who wish to promote cultural change, whether by use of a contract, or other means, research into this process is imperative.

The research is still at an early stage and our objective in this paper is merely to present some methodological considerations and to illustrate some of the obstacles which the NEC will have to overcome.

\section{The Culture of Research.}

In addressing these aims, we are somewhat hampered by assumptions which exist in the present culture of project management research, itself. Chief among these is the belief that it is possible to attain an objective viewpoint, from which facts about culture may be established. Such facts are then expected to operate as a corrective to the misconceptions of practitioners - to be used to adjudicate between the biased views of various interest groups. This conception is misplaced. We are dealing, not with facts as opposed to values, but with facts about values. Cotgrove (1981) makes the point very clearly in the context of the controversies about environmental pollution. Following the anthropologist Mary Douglas, he points out that 'pollution' is itself a value concept and that no amount of fact is capable of resolving value differences between the parties in dispute. However, it is possible to use objective criteria or facts by which those in dispute can express what specific action or remedies they require.

The distinctions between facts, values and facts about values, have important implications for both practitioners and researchers. From a practitioner's point of view, value differences at issue amongst people who must work together may not be resolvable and compromises upon specific issues will have to be negotiated. This point will be taken up later. From the researcher's point of view, our only conceivable source of data on matters of value, i.e. the facts about values, is the expressed views, desires, wishes, and so on, of the practitioners themselves. What emerges from the assemblage of a number of such viewpoints is not a coherent picture of a 'culture' or an organisation, but a series of more or less conflicting versions. The resolution of these conflicting versions by reference to some 'meta-version', is not logically possible.

Rather, it is a practical problem for practitioners. For the researcher to take on the task of resolving the differences, is to usurp the practitioners' role - it is to distort the data, by reading one's own assumptions and preferences into them. 
There are three major consequences for our research. First, the reader may find views expressed in our data to be morally objectionable, or factually wrong. In particular, since it is our aim to identify potential sources of resistance to the NEC, we will be reporting views to which supporters of the contract may take exception. We make no apology for this. It is not our business either to criticise or endorse the views we report. We present them purely as facts about values: evidence of existing attitudes within the industry.

Secondly, our analysis proceeds from the presentation of conflicting values to the analysis of some of the ways in which people attempt to promote and transmit the particular values they hold. We make no attempt to pre-empt the outcome of such a process.

Finally, the discussion of the implications of our findings, which is presented at the end of the paper, must be read has having a different status to the rest. Here, we are exploring the logic of a situation we have previously only described. This is not a report upon empirical findings, but an attempt to assess the significance of those findings. In contrast to the earlier reporting of the views of others, we are here expressing our own.

\section{Conventional Research Method.}

Elsewhere, we have criticised the traditional approach to construction management research as a misconceived attempt to extend the methods of engineering research into the sphere of human relationships (Seymour and Rooke 1995). This leads to a mechanistic treatment of culture as a finite and measurable entity, which can then be treated as a variable in a causal model of managerial behaviour. There exists a long tradition of criticism of this approach in social studies.

One of the best known works to adopt a mechanistic approach is Hofstede's (1980) massive comparative study of national cultures. In this important work, Hofstede reduces culture to four dimensions, against which national cultures are measured by use of a questionnaire survey. We see several problems with this. First, the results offer such broad generalisations about such large groups of people that they can not be regarded as reliable in any specific situation. Second, the development of the 'dimensions' suffers from an ethnocentric bias, being derived themselves from the language and concepts of Anglo-Saxon America. Thus, all cultures are described in terms of the researchers' own culture. Third, the rigidity of the questionnaire survey procedure prevents the correction of mistaken assumptions in the course of the research. Hofstede has more recently added a fifth dimension to his original four, it is significant that he has only been able to do so by drawing upon the work of the ethnographer, Pradhan. (Hofstede 1991) Pradhan, a Nepalese anthropologist, concluded from his work in a Dutch village, that an important cultural difference between East and West resided in the relative values accorded to truth and virtue. While Westerners, he argued, tend to value truth more than virtue, in the East virtue is valued over truth. The point here is that Hofstede's original methodology was incapable of recognising this difference. Finally, Hofstede's work is premised on the assumption that a culture can be adequately described in terms of a set of quantifiable dimensions. We take the view that culture is a matter of the exercise of judgement (Winch1990; Garfinkel1984). We regard an account of culture which does not leave room for these judgmental decisions on the part of the culture's members as inadequate. 
The popularity of Hofstede's offering and others like it is understandable. People do things differently and the idea that these differences can be systematically and objectively identified and compared is very attractive. It is thus a natural and inevitable starting point for the investigation of culture. It is, however, only a starting point. Culture is primarily about ways of seeing things (Eglin1980). A proper understanding of another culture consists in a knowledge of how things are seen from within that culture. To see all cultures in terms of one's own, reducing all points of view to a single perspective, is to overlook the very essence of the phenomena we are trying to describe. The practical consequences of this deficiency become apparent when the question of how cultural change is to be achieved is addressed. If people are to change, they must be persuaded. In order to persuade someone it is necessary, first to understand their point of view. It is this understanding that is missing from the Hofstedian account of culture.

Thus, we see this approach as having a limited practical application. The ability of some researchers to multiply the number of measurable dimensions and produce impressive visual representations of the results (Maloney and Federle 1993) or to combine a multitude of analyses (Lansley 1994) does nothing to remedy this essential limitation.

It is perhaps worthwhile to stress that it is not the methodological integrity of the studies cited above that we are criticising. On the contrary, our argument is that however fastidiously and intelligently these research methods are employed, they will nevertheless fail to come to grips with the phenomenon of culture. This is because it is the assumptions upon which these methods are based which, in our opinion, are flawed.

\section{An Alternative Approach.}

The interpretivist research strategy which we are pursuing attempts to avoid the trap of making generalisations about other people's culture with insufficient attention to the way such culture is experienced by them. The question which the strategy raises is, in short: what does the world looks like to the other fellow? Crucially, it addresses questions of value which conventional methodologies ignore. Questions as to what future direction the industry should take, what behaviour is acceptable and what is not, what the aims of a construction project should be, are all essentially questions of value. They all call for judgements which it is the business of participants in the industry to make. It is not within the remit of the researcher to pre-empt such decisions. By ignoring such questions, however, conventional methodologies can allow them to be answered by default, often in terms of the researcher's own unexamined values. By abandoning the pretence of scientific objectivity and making the views of people in the industry our primary data, we seek to deal with questions of value in a way which does not involve introducing our own covert value judgements.

Our approach is based on the ordinary methods of gaining social understanding which are employed by all members of society. Ultimately, it is intended to monitor the operation of twelve contracts, six NEC and six others. The material cited in this paper is drawn largely from conversations with approximately thirty people from different backgrounds in the industry. The length and nature of these conversations has varied from short telephone calls at one extreme, through group discussions, to a series of three interviews totalling seven hours, at the other. A tape recorded interview of up to two hours, would be about typical. In the section on legal culture, the main sources have been written materials. 
We take it as an essential first principle that cultural phenomena can only be regarded as having objective existence inasmuch as they occupy such a status in the conceptions of members of the industry. To the extent that we treat culture as an objective phenomenon, therefore, the focus of study becomes the ways in which members of the industry investigate and display the objective reality of culture. The nature of the culture which is thus established is a matter for members and the researcher has no privilege in this matter. A researcher's version of the industry's culture can have no more validity than that of any other member. The most researchers can hope to do, is to report the points of view which are expressed to them in an adequate way.

\section{Culture as a Researcher's Concept.}

We will make two different uses of the word 'culture'. In understanding these uses, the conception of culture outlined by the anthropologist Roy Wagner is particularly useful. Wagner (1981) points out that the meaning of 'culture,' as well as referring to the established norms to which people adhere, also encompasses their creative endeavours.

We will use the word, first as a way of referring to the subject of research. Thus, all the knowledge, beliefs, opinions, speculations, talk and activity of members of the industry are included. This may be summarised as the habits and capabilities acquired by practitioners as members of the industry. ${ }^{2}$ In this context, the 'objective facts' of social life are seen to be intersubjectively created, constituted wholly from the subjective meanings attributed to situations by individuals. They are not created for once and all, however. Rather, they are routinely re-invented by different individuals in continually novel and unique situations. Thus, the concepts we use when describing the culture of the construction industry - individuality, confrontation, profitability, safety, quality, contract, profession, company, etc. - do not have a fixed meaning, but vary in their use according to the situation and the users' intentions.

There are two issues here whose importance to the conduct of the research needs to be made clear. The first concerns indexicality and the second concerns the creative nature of our own analysis. Indexicality refers to the fact that we need to know the context in which something was said in order to understand its meaning To give a rather crude example, one supporter of the NEC told us:

"I'm convinced, with the right people, with the right procedures and tenure, you can achieve the same by a handshake across the table. I don't think it matters a jot what the contract is."

Taken out of context, this might be interpreted as a dismissal of the NEC. It is only our knowledge of the context in which this statement was produced which allows us to assure the reader that it is nothing of the kind. The talk which came before and after this statement makes it quite plain that the speaker regards the contract as making a major contribution to improved relations between client and contractor.

${ }^{2}$ We are grateful to Professor Edward Rose for drawing our attention to the form of this definition, which is derived from the 19th century anthropologist, Edward Tylor. 
Second, Wagner stresses that the process of creation applies equally to the concept of culture itself and to researchers like ourselves who make use of it. Thus, 'culture' is an invention which is used to explain differences between groups of people. It is in this light that the categories we use in our analysis, such as 'claims culture,' or 'technical order,' should be read. The culture which is being studied is created by the researcher and informant in a process of communication. This process of creation is, of course, itself cultural: the culture which is created between a researcher and an informant will be in many ways unique. There is no method by which we can escape the essential subjectivity of this process, but the perspective which Wagner gives us allows us to see our creations for what they are.

\section{Culture as Practitioners' Concept.}

Secondly, when discussing occupational, professional or corporate cultures, for instance, these terms should be taken to refer to what members of the industry take them to refer to. This is because it is a key principle of the interpretive approach which we use that the researcher attempts to discover what the world looks like to the members of the social situation under study. In creating the informants' culture, the definitions used will be those definitions which are given to us by our informants. Since 'culture' is something of a 'buzz-word' in the industry at present, we must be careful to distinguish between our own uses of the word and the uses made by our informants. Furthermore, we have no warrant to privilege our own interpretations as more insightful than those of our informants. Any rediscription of informants' accounts runs the risk of distorting the data. As Wagner puts it,

"every anthropological undertaking stands at a cross-roads: it can choose between an open-ended experience of mutual creativity ... and a forcing of our own preconceptions onto other peoples.” (Wagner:16)

The interpretivist approach is in many ways a literary one, in that it consists of identifying and describing the 'themes' of a cultural setting, as they are manifested in the actions of its members. The basic research strategy, then, consists of observation and description.

The initial technique which we adopt is the unstructured interview. The advantage of this technique is that it is possible to follow where the informants lead, identifying the themes and issues which are important to them and following them up. As the research progresses and the concerns that are relevant to the members of the culture emerge, it becomes possible to adopt a more structured interview schedule, though scope is always to be left for informants to lead the discussion. The main disadvantage of the technique is that it consists largely of people describing their activities, rather than performing them. We will be attempting, therefore, to supplement the interview data with direct observation. This may consist of participant observation, shadowing, or some other form of non-participant observation.

\section{Professional Cultures.}

With regard to the (non mathematical) analysis of data, the interpretive perspective abounds in possibilities. Initially, following Strauss et al (1963), we are treating the construction project as a negotiated order. This approach has certain deficiencies, which we will attempt to remedy, drawing on some of the insights achieved in the study of ethnomethodology.

Strauss says of the negotiated order approach that it is appropriate: 
"whenever an organisation possesses one or more of the following characteristics ... : if the organisation firstly utilises personnel trained in several different occupations, or secondly, if each contains an occupational group including individuals trained in different traditions, then they are likely to possess somewhat different occupational philosophies, emphasising somewhat different values; Then also if at least some personnel are professionals, the latter are likely to be pursuing careers that render them mobile - that is carrying them into and out of the organisation" (Strauss et al 1963:169)

Strauss' approach involves the identification of distinct professional ideologies or subcultures then attempts to establish how adherents to these assert their own values in the face of competing ones, how they form alliances and enmities, make concessions and compromises and, through this process, establish working routines.

A previous study, carried out in the early 1970's, illustrates this processes (Seymour1986). This study identified two separate orders of legitimacy in the industry, the technical and the economic. These imply the recognition on the part of participants that there are norms and conventions which govern the way people seek to optimise their economic interests and there is a different set of norms and conventions which govern the way buildings are designed and constructed. They coexist but sometimes they conflict as when, for example, a QS insisted that a pump, ordered to site by an engineer for the technically necessary purpose of draining a trench, be sent away until it was authorised by the RE who would, thereby, accept the cost of its hire on the behalf of the client. The water, it seems, was entering from an underground source and was therefore not the responsibility of the contractor.

It is significant that it was the engineer who responded to the norms of the technical order, while the QS responded to the norms of the economic. Thus, those orders which are implicitly invoked can be used to categorise members according to the nature of their work. The contract documents have different value relevance among the different occupational groupings and relations between these groupings have an important impact on the administration of contracts.

This may be seen from another example. An engineer in the civil engineering division of one construction company related the following history:

"There was a time when engineering was a centralised service... the agent asked for engineers out of the pool. The engineering service idea stemmed from our building activities, where line management - site agents - were not engineers, but tradesman or ex-quantity surveyors, and required an engineering service. Engineers were used on site in a service role, and had no executive authority. Many engineers took the veil, and went into line management, and didn't touch engineering again. However, about five years ago, we in the civil engineering division got hold of our own engineers, and are now giving them their own careers; we are getting this service thing out of the system.” (Seymour1986:200)

This increase in status for engineers (as engineers, rather than as managers) is accompanied by a change of status for quantity surveyors.

"It's the same with quantity surveyors. Due to our building ancestry, they were until recently, a race apart, independent. Their job was to get as much income from the client as possible, while the site agent's job was to construct as cheaply as possible. Since we became semi-detached from building, 
quantity surveyors have now become part of the management team on site.

They didn’t like this loss of independence at first...” (ibid)

In the view of the engineer quoted above quantity surveyors, as long as they retained their independence, chiefly occupied themselves with the use of the contract to increase income from the client. When they became part of the team, however, this function no longer retained the same importance. For engineers, the commercial issues tend to be more peripheral, as their primary concern is with the actual work of construction.

Some of the changes proposed by the NEC are similar to those described above. The reduced importance of Bills of Quantity and the emphasis on planning, have implications for the QS's role. On one hand, we have found that some engineers who support the NEC regard it as a means of reducing the influence of QSs, whom they regard as responsible for many of the problems of the industry. On the other hand, the NEC's emphasis on planning is seen by some QSs as an opportunity to extend their professional skills and become more centrally involved in the construction process.

\section{Limitations of Negotiated Order Approach}

A problem with the Negotiated Order approach, is that it involves a tendency to reify the subcultures under discussion, that is, to attribute to them a 'thing-like' status, losing site of their essential nature as social processes. To differentiate between cultures is to participate in a process of labelling. Typical features of a particular group are assembled in the form of a kind of template, which can then be applied to individuals to assess their status as members of a particular category. The assumption, inherent also in an approach like Hofstede's, is that a given population can be simply divided into a number of equivalent groups, which can be described in an objective manner. This is mistaken, however. The actual uses of language are much more subtle. For instance, a commercial manager told us:

"the other side have... the engineer's mentality...they don't want to know.”

This is typical of the kind of complaint which is often heard. Engineer's mentality cannot be regarded as a consistent feature of a group, however. Because, as the same manager also observed:

“...that does happen, that clearly does, where you can't get an engineer to make a decision and so nothing happens ... and that's obviously what we want to get away from. But that comes from an engineer who shouldn't be in that position..." 
There is an apparent contradiction here, in the picture of engineers which emerges from the commercial manager's account. This contradiction results from our desire to identify the consistent features of 'the engineer,' in order to establish a picture of the 'engineering sub-culture.' In fact, the statements quoted above were not made in order to facilitate the creation of such a picture. The first was designed to express the manager's frustration with the engineers 'on the other side' of the contract. The second was made in defence of the ICE form of contract, after the interviewer had suggested that it can lead to situations where work has to stop. The point here is that the characterisations of different groups within the industry are resources upon which members may draw for a variety of purposes. At the outset, we have no certainty of what the range of such purposes may be; it is only in establishing this, that anything meaningful may be said about such characterisations.

A similar point has been made about organisational rules (of which contract clauses are an example), these rules are not followed mechanically. They are used by members of the organisation as and when they seem appropriate. For example, as long as they facilitate the work process, they act as resources, if they become an impediment to the process, due to unusual conditions, they may be suspended (Bittner1965, Zimmerman1971). It is this which makes it important to ground observation in member's understanding. Valuable work has been done in this regard by Sacks (1972). By identifying social categories as elements of individuals' sense making procedures, Sacks makes possible the empirically grounded description of social order. Cuff (1993) extends this work by applying part of Sacks' analytical machinery to the analysis of differing versions of events.

We are seeking to establish, therefore, descriptions of two different kinds of phenomenon. First, profiles of cultural types within the industry. These are given in our broad generalisations, such as 'claims culture,' or 'technical order.' Second, the methods by which members of these cultures establish and display the reality of those cultures. These are given in the descriptions of the ways different groups in the industry are characterised by others in the normal course of talk. (Such as the example given at the beginning of this section.) It is only by examining the latter that we will be able to assess the possibilities of change, because it is only in the latter that we come to grips with concrete social reality.

The above constitutes only one of several possible ways of analysing data. The choice of analytic approach is not one that should be settled at an early stage of the research, but should be dictated by the nature of the findings. This is something that is often tacitly assumed in the best research, but is not made explicit in the reporting of that research. As already stated, we regard our primary data as being the perceptions of those among whom we research, any attempt to impose a rigid, preconceived analytic structure upon this data, only has the effect of distorting it.

\section{Legal Culture.}

We have observed that obstacles to cultural change can arise from the perceptions of particular groups. People's common sense views of the world function to arrange the world around them. Our own tasks in the everyday world of working are seen by us as central to the world. Our perception of the world is, indeed, arranged in accordance with the priorities demanded by the work in hand (Schutz1971).

It is our impression that, by and large, lawyers have not given the NEC a warm welcome, though of course there are some who have done so. As noted earlier, occupational cultures are not fixed entities in which all members exhibit identical and 
unchanging values, beliefs, strategies etc. As also noted, a major concern of the research is precisely to record the process by which they do change. In this section, we review four papers by lawyers in order to establish the particular line of reasoning which seems to underlie the unreceptive attitude. We detect two: the first, is to do with lawyer's role as interpreters of contracts; the second is to do with their role as designers of contracts. It is perhaps worth reiterating, at this point, our perspective on the views expressed. We neither endorse, nor reject them, but offer them as evidence of attitudes which currently exist within the legal culture. In addition, we must beg a certain indulgence. We are not experts in contract law and our understanding of the materials referred to in this section is necessarily superficial. Nonetheless, we feel that we have identified sufficient evidence for the motivations identified above.

Lawyers will naturally see a construction project in terms of the law. A contract like the NEC, which attempts to move the emphasis away from legal concerns towards task oriented ones will nevertheless tend to be seen by lawyers in legal terms. Their role is to anticipate what might happen if the parties to the contract enter into dispute: to anticipate how contractual provisions would be interpreted in a court of law. As members of a legal culture, they are employed precisely for the insight this membership gives them. The direction construction contracts have conventionally developed has consisted in designing clauses which will defend the interests of one party or another, in the event of dispute. This has the effect of reducing lengthy and costly disputes, since the outcomes of disputes which arise are foretold in the contract clauses and the body of case law.

One of the motivations behind the NEC contract, is also to reduce the occurrence of disputes. However, under the NEC, possible sources of dispute are treated in a fundamentally different way from that in more conventional contracts. Under the NEC, the intention is that disputes are to be avoided through good management practice, which reduces the incidence of conflict. While it does address the matter of how disputes may be equably resolved, its primary emphasis is on how they can be avoided. The aim is transparency; bad management is to be penalised, not insured against.

The idea that good management practice can be promoted through the wording of a contract is ignored by Jones (1995). On the question of whether a contract can promote co-operative relations, he cites four factors which he considers to be of greater importance; ironically, one of these is "inadequate management by contractor." (ibid 13.2, our emphasis) Inasmuch as he considers the role of contract wording, in this context, he only does so with regard to "'atmospheric' conditions." (ibid 13.5) such as those calling for "all parties to deal fairly with each other." (ibid) He objects to such a condition on the grounds of vagueness. Referring, however, to the existence of "a real mood for change away from conflict..." (ibid 13.3). He concedes that a new contract might have a psychological effect "even if the detailed working was much the same.” (ibid)

Cornes (1995) recognises the intention of the NEC to promote good management practice, but passes over it largely without comment. He expresses deep concern over the novel wording of the contract and the absence of existing case law to assist interpretation. Cornes also asserts that the NEC is harder to understand than the legal wording of more conventional contracts. The researchers find this view difficult to understand, but it does have considerable support among our informants in the industry. One detractor of the NEC asked, 
"Why change wording which everybody understands?"

Secondly, lawyers are themselves in the process of contract design. Perceived problems in the industry and the possibility that they can be alleviated by better contracts, leads them to propose their own solutions. In these discussions, the NEC is often used as a foil against which their own proposals may be made. Thus Uff (1995) in arguing for a more radical approach to handling the time element in contracts, comments that:

"Just as no available standard form contract available offers fixed performance periods, so all such contracts, including the NEC, deal with delays in the same conventional manner, in terms of "excusable" and "compansable" (sic) delays, and extensions of time. The language may change, but the effect does not." (ibid p5-6)

Uff's paper is unique among the four considered here, for its attention to management issues. Craig (1994) while also proposing innovations in contract design, is again concerned with the consequences of disputes. The first part of his paper compares three features of the NEC and Electrical Contractors' Association contracts: completion; retention; and security of payment for contractors. In the second part, he makes some suggestions of his own: that the aims and objectives of clauses should be drafted into contracts. We are unable to detect the connection between the arguments in the first half of the paper, and those in the second. It is apparent, however, that the first half of the paper is concerned with facilitating the settlement of disputes; the second with proposals regarding the design of contracts.

\section{Claims Culture}

The role of contracts in the negotiation of order has received little attention. It is apparent from the outset, however, that the contract signifies a major divide between the client and contractor. What follows is a tentative description of the culture of these two groups, with regard to the question of claims.

The 'claims culture' may be described in terms of four types of viewpoint. Two of these refer to the client and two to the contractor. The integrative and distributive views can be seen as opposite poles on a continuum of attitudes. These viewpoints represent pure or ideal types (Weber1949) and do not describe the views of any particular individual: an individual may hold a mixture of views, or may express different views in different contexts. Nor do they necessarily exhaust the range of views which might be held. They merely act as a guide, by which individuals may be categorised and their attitudes and actions predicted, in certain specific circumstances.

Contractor's View - Distributive. The client is out to get the best possible deal by 'screwing' the contractor at every opportunity. It is therefore both necessary and just that the contractor should adopt the same approach. Since clients are stupid as well as greedy, by and large, contractors will always get the better of them.

A combination of heavy price competition and inadequate design and method statements means that contractors must quote for low or non-existent profit margins. This is so because any opportunity to increase income by exploiting omissions or mistakes in the contract data, will be used by competitors and be reflected in tender prices. This practice effectively punishes the client for sloppy design work, since a well thought out brief will provide no opportunities for claims.

Contractor's View - Integrative. The aims of any project are to do a good job, on time and at contract price. The best way to achieve this is through developing co- 
operative relationships with the client, which contribute to a more pleasant and efficient working relationship. Nevertheless, profitability is an issue of survival and where it is threatened, overshadows other considerations. Soft contractors will try to avoid unprofitable contract prices, but may be forced by competition to become claims conscious.

Client's View - Distributive. The aim of procurement is to get the job done as cheaply as possible, the contractor's profit is not a consideration. Contracts should be designed to bind the contractor hand and foot, for contractors will cheat the client if they can.

Client's View - Integrative. The contractor's profitability is essential to the health of the project and to the industry as a whole. Fair-minded contractors will act in a reasonable manner, if they are treated fairly. Nevertheless, many contractors will attempt to 'put one over' on the client and this possibility must be guarded against.

It is important to recognise the limitations placed upon members' actions by the constraints of the economic order. This is not the place to launch into an investigation of the economics of the industry, it is sufficient to note one important aspect. Several of our informants, as well as the industry press, have pointed out the tendency for contractors to submit tenders at a price which allows only a narrow, non-existent, or even negative profit margin.

Competitive tendering is the crucial mechanism by which competition is carried out in the industry. To the extent that clients allow price to be the sole criterion in selecting tenders, this has the effect of producing unrealistic tenders. This is because contractors will compete, not only on price, but on their ability to generate additional income from changes. This practice leads, in turn, to adversarial relationships.

It is often commented that the construction industry is fragmented. The temporary nature of projects and hence, of working relationships, presents particular obstacles to the development of trust and co-operation. In such an environment, individuals do not have to live for long with the consequences of generating ill-feeling. Thus, there is no strong social pressure to counteract the effects of competitive tendering. In classical economic theory, the overriding market force is customer satisfaction, which generates more sales for firms. The nature of the industry militates against the effective operation of this mechanism, however. Since tendering often operates on a national basis and since many clients commission only the occasional project, the incentive to win more work by pleasing a client may be relatively low. This is particularly the case if clients focus on price rather than quality. It may also be the case that particular organisational structures among contracting companies tend to encourage this fragmentation.

The early resolution of commercial issues raised by variations, which is insisted upon in the NEC, is one way of ensuring that social pressure is brought to bear upon those whose behaviour appears unreasonable to the other party in the contract. Individuals must at least live with the consequences of their actions until the end of the contract. In conventional forms, where settlement is left until the very end, this is not the case.

\section{Conservatism.}

A major obstacle is natural conservatism, people simply like to go on doing things in the same way and no innovation, however beneficial it may be, will be welcomed unreservedly. There are, moreover, practical reasons for this, as one member, working under an NEC contract remarked of his colleagues: 
“If they get problems, they run back to what they've been doing for 20 years... You've got hundreds, if not thousands of years experience between them... people don't forget what they've learnt over the past twenty years, not easily anyway."

In addition, people may not recognise the NEC diagnosis of the problem: they may be satisfied with the way things are. Many contractors, for instance, assert that they are not claims conscious and that their planning is efficient. Thus, when it is suggested that the NEC has the effect of reducing conflict and improving planning, they are not impressed. In speaking to others, we get the distinct impression that they enjoy the claims culture, the excitement of 'getting one up on the other side.'

Many see problems, but doubt that the NEC provides a solution to them. Some contractors point to the low profit margins in the industry as the chief source of problems. Others mistrust the motives of those promoting the contract, seeing it as an attempt by client's to 'get one over' on the contractor, for instance. Conversely, some clients mistrust the contract, fearing that it does not properly represent their views.

\section{The Transmission of Culture.}

In the previous sections, we have identified ways of reasoning which are not conducive to the aims of the NEC. It would be possible to cite others which are supportive of those aims. An important question for supporters of the contract is, how might the latter prevail over the former? This brings us to the question of cultural change and how such change occurs. It is only possible to make a few remarks about such processes here, it will be a focus of future research.

One of the major ways in which it takes place is through imitation. One senior manager in a large client organisation told us.

"I've worked with a brilliant director, for fifteen years, off and on. I was his deputy, I got fairly close to him on the last job. I've always been about three or four levels below him, I'm about two now. But, he's always been there and you can always see how he approaches things. Even though I was sort of three positions removed, I've been in a situation with him numerous times where he's been brought in to sort out problems."

In this case, the manager is treating one of his superiors in the organisation as a mentor, or role model. This requires the main motivation to be on the part of the recipient, which presents obvious problems for those who wish to bring about a change in culture. The charismatic leader can attract and influence people, but charisma cannot be bought in like material imputs. It is rather a question of levels of commitment among managers and the setting of good examples.

A second way in which people actively try to promote culture is through the telling of stories. We were shown a safety film which had just been made. A client's manager told us about an accident that had occurred:

"The ill fated incident, did you hear about that? [shows us a board of photos depicting the scene of an accident.] The dump truck actually broke through, see where all that railing's bent there was screed being taken up this ramp here and the dump truck was going by and the tail end slipped down there and fell seventy foot to the ground, didn't touch the ground cos of the mesh reinforcement below. It was coming down end first, it shed its load on the way down, the driver miraculously didn't get killed, he was actually found 
huddled up in his cab, we actually had to get the fire service to burn out, he wouldn't come through the door opening, through the window bit. So we had to burn a hole in the side to pull him out. We eventually found out he'd got a fractured skull, but at the time he was still subconscious. There were six men down there. Two on top of the mats fixing and there were four underneath it and because they heard the guard rail give they scrambled to safety. One actually froze where he was on the top and I think it actually landed at his feet. But that gets your mind working on what your main priorities are and what you actually, what your culture is on safety etc."

We would suggest that the manager has a complex of related motivations in telling this story. He wishes to demonstrate his commitment to safety, to explain it by telling us about an event which has had a powerful effect on him and to present this demonstration and explanation as a true-story-with-a-moral. It forms a part of the manager's attempt to promote a culture of safety, along with measures such as safety films.

Telling stories is, of course, one of the methods we have used in this paper, to describe culture. This highlights the symmetry between research and practice.

Another important method of cultural transmission, the last we shall consider here, is anticipative socialisation - treating people as if they behaved as you expect them to behave. By attributing approved motives to another's actions, one simultaneously explains the approved culture, while extending social approval to the other. This puts the other in a situation where to act in a non-approved way leads to the sacrifice of social approval.

Anticipative socialisation is a very powerful though risky method. It means that a set of expectations is held of someone, whether or not there is any prior evidence that those expectations are warranted. The person is then treated according to the expectations and subsequent behaviour is treated as evidence that the expectations are warranted. The common sense description of this process of influencing behaviour is the self-fulfilling prophesy. A good example is McGregor's (1949) so-called Theory Y and Theory X: we can assume that people are all basically lazy, will avoid work and responsibility if they can (Theory $\mathrm{X}$ ). Treated like this, the evidence is that they will conform to the expectations. On the other hand, we can assume that work is sought as naturally as eating or breathing and that people will respond positively to treatment based on this assumption (Theory Y). This is not to say that people will invariably conform; like any form of socialisation, there is no guarantee that it will work.

Nonetheless, Fisher and Ury base their excellent book on negotiating practice, Getting to Yes, upon it. They suggest that both parties to a negotiation can get more from it if they focus on outcomes that will optimise the parties' respective interests to achieve a win-win solution. What commonly happens in conventional negotiating, they suggest, is that people are too concerned to protect and promote their position, that is, a conception of what they want before they have considered what the other party might want and may be able to offer, if the negotiations are entered into in a positive, mutually creative frame of mind. So long as both parties treat the transaction as a shared problem - the need to come to a win-win solution - then behaviour which might otherwise be interpreted negatively (as an attack, an insult, sheer bloody-mindedness), can be treated as part of the problem which needs to be jointly solved. So, for example, when one party digs his or her heels into his/her own position, the problem is to establish what particular reasons are leading him/her to do this rather than seeing it as evidence of an intrinsic and irremediable behaviour trait. Fisher and Ury insist 
throughout the book that this is not a question of being 'nice' or 'soft'. It is a practical way of dealing with disagreements, based on the assumption that there is always 'more on the table', i.e. many more solutions available to improve the benefit to both parties, if it is assumed that taking a positive view of the other will enable whatever is on the table to be seen more clearly.

The implications for culture change and, in particular, for changing the alleged confrontational culture of construction, are clear. This is not the place to go into further detail of 'how one deals with people who won't play ball' or 'who are much more powerful than oneself', however, Fisher and Ury demonstrate very persuasively how the power of anticipative socialisation can be used to produce outcomes where greater benefit is obtained by both parties.

We already have extensive evidence of the use of anticipative socialisation which may be serving to perpetuate the habits of confrontation and some which may bring about changes in attitudes and behaviour. For example Gale (1993) shows that in construction, people are expected to act aggressively, assertively, decisively, and, generally, to adopt a 'macho' style. Any attempt to act supportively or more reflectively is treated as deviant or as likely to disguise some 'real' motive more in line with the expectation. Thus, women in construction are 'difficult to get on with' because their behaviour is said to be erratic or unpredictable. From the perspective of anticipative socialisation, the method is failing to work - women are not conforming to type, though of course some do and are likely to be welcomed as 'good chaps'. To the extent that the method does not work, more direct and assertive methods of control are likely to be used to the extent of claiming that women are unsuited to construction work and should not be employed.

These then are just three of the methods by which cultures evolve. While understanding such processes puts those who consciously wish to engineer or manage change in a better position, they are not to be seen as providing 'sure-fire' recipes. Culture is above all a subtle and complex process.

\section{Discussion.}

In concluding this paper we repeat a number of points already made. Our intention in the research is to be able to report on specific cases which enable the significance and meaning of statements and events to be more easily communicated. Here, we have used comments based largely on the work that has been done to date for illustrative purposes and we by no means intended to convey a comprehensive, or representative view of the existing culture of the industry.

In outlining our research to date, we have identified three cultural forms that exist as potential obstacles to the successful adoption of the NEC. Two of these obstacles arise from differences between professional groupings, the other from the economic culture of competitive contracting.

It is too early in the research to assess the implications for the success of the NEC of the existence of different professional norms and consequent status rivalry between engineers and quantity surveyors, for example, or the impact the contract's adoption will have on them. However, we see a vital need for further attention to this issue. If the contract were to come to be seen by QSs as favouring the interests of engineers above their own, this would only serve to increase resistance to its effective implementation. An alternative exists: under the contract, QSs can be drawn closer to the construction process and into the necessary process of planning. 
A more easily apparent source of resistance to the NEC is the legal profession. We have observed that the legal culture attempts to pre-empt disputes by predicting their likely outcomes. The putative culture of the NEC attempts the same thing by promoting good management practice. Given this contrast, the choice may be seen as one between pursuing an argument about techniques of good project management, in order to avoid problems arising, or an argument about contract law, to enable problems which have already arisen to be settled equitably. We have suggested that lawyers naturally tend to focus on the latter, they have no special expertise to enter into debate about the former. Thus, it is unsurprising that those lawyers whose comments we have reviewed do not address the underlying principles of the NEC.

We suspect that the problem for supporters of the NEC is that lawyers will be seen as those best qualified to comment upon the effectiveness of contracts. Thus, there is a danger that the 'good management' solutions to the problems presented by the contract will be overlooked. There is a certain circularity about this situation: it is, after all the lack of good management in the industry that the NEC sets out to address. We suggest therefore, that the contract alone is not capable of overcoming this situation. If there is not a simultaneous drive to advertise the issue as being a choice between good management practice, or adversarial relations, then the contract will be judged by the criterion of conventional contracts - on its ability to act as a shield in the event of conflict.

With regard to economic considerations, the success of any form of contract is unlikely if contractor profitability is seen to be unduly restricted. Thus, if tenders are prepared on the basis of habits and expectations learnt over many years, the contractor will find himself committed to a price which he had expected to be able to augment in the time-honoured ways. To the extent that this happens, he is likely to be unsympathetic to the contract and unwilling to commit the time and effort to leaning how to use it. Alternatively, if the contract achieves a reputation for holding down the outturn price, then contractors will bid accordingly. We suggest therefore, that innovations in tendering procedures, to allow clients to assess the quality of the tender and the attitude of the contractor, along with training in the use of the contract, will be important to the initial success of the NEC. None of this is intended to detract from the very real possibility of savings being made through better project management. With regard to this, however, our argument would be similar. It is only to the extent that contractors are aware of the implications of the contract that they will achieve these benefits.

More generally, we do not believe that a contract can alone transform the culture of the industry. A future focus of research will therefore be into methods which may be used alongside the NEC, in order to promote the values which it embodies. In this article, we have examined three modes of cultural transmission, as a preliminary step in this direction.

\section{References.}

BITTNER,E. 1965 'The Concept of Organisation' in Social Research, 32.3 reprinted in Salaman \& Thompson (eds.) People and Organisations, Longman, London.

CORNES,D. 1995 'Legal Implications of the NEC,' paper delivered at the School of Business and Industrial Management, 3rd February.

COTGROVE,S. 1981 'Risk, Value Conflict and Political Legitimacy,' in R.F.Griffiths (ed) Risk Management, Manchester University Press, Manchester. 
CRAIG,R. 1994 'Drafting Contracts and Constructing the Team,' RICS/West Midlands CPD lecture, 22nd November, 1994.

CUFF,E.C. 1993 Problems of Versions in Everyday Situations, Washington, University Press of America, Washington DC.

EGLIN,P. 1980 'Culture as Method: Location as an Interactional Device,' in Journal of Pragmatics, No 4.

FISHER, R. and URY, W. 1990 Getting to Yes, Hutchinson Business, London.

GARFINKEL,H. 1984 Studies in Ethnomethodology, Polity Press, Cambridge.

GALE,A.W. 1992 'The Construction Industry's Male Culture Must Feminize if Conflict is to be Reduced: The Role of Education as Gatekeeper to Male Construction Industry' in Fenn, P. and Gameson, R. (eds.) Construction Conflict Management and Resolution, E. and F.N. Spon, London.

HOFSTEDE,G. 1980 Culture’s Consequences, Sage, London.

HOFSTEDE,G. 1991 Cultures and Organisations, McGraw-Hill, London.

ICE 1993 The New Engineering Contract: Guidance Notes, (first edition) Thomas Telford, London.

ICE 1993 The New Engineering Contract, (first edition), Thomas Telford, London.

JONES,N. 1995 'Legal Implications,' in The Latham Report: Course Documents, Birmingham, Construction Study Centre.

LANSLEY,P. 1994 'Analysing Construction Organisations,' in Construction Management and Economics, 12:337-348.

McGREGOR,D. 1960 The Human Side of Enterprise, McGraw-Hill, New York, NY.

MALONEY,W.F. FEDERLE,M.O. 1993 'Practical Models for Organisational Assessment' in Journal of Management Engineering, ASCE, 9.1:64-81.

MAYO, E. 1945 The Social Problems of an Industrial Civilisation, Harvard University Press, Cambridge, Mass.

PETERS,T.J. and WATERMAN,R.H. 1982 In Search of Excellence, Harper and Row, London.

SACKS,H. 1972 'An Initial Investigation into the Visibility of Conversational Data for Doing Sociology,' in D.Sudnow(ed) Studies in Interaction, Free Press, New York, NY.

SCHUTZ,A. 1971 'On Multiple Realities,' in Collected Papers: Volume One, Martinus Nijhoff, The Hague.

SEYMOUR,D. 1986 The Place of Organisation Theory in the study of Construction Management, $\mathrm{PhD}$ Thesis, University of Birmingham.

SEYMOUR,D. and ROOKE,J. 1995 'The Culture of the Industry and the Culture of Research.’ in Construction Management and Economics (forthcoming).

STRAUSS,A. SCHATZMAN,L. BUCHER,R. EHRLICH,D. SABSHIN,M. 1963 'The Hospital and its Negotiated Order' in E.Friedson (ed) The Hospital in Modern Society, Macmillan, London.

STRAUSS,A. SCHATZMAN,L. BUCHER,R. EHRLICH,D. SABSHIN,M. 1964 Psychiatric Ideologies and Institutions, The Free Press of Glencoe, New York, NY. 
UFF,J 1995 'The Unrealised Potential of Construction Lawyers,' paper delivered to Society of Construction Lawyers, inaugural meeting of West Midlands branch.

WAGNER,R. 1981 The Invention of Culture, The University of Chicago Press, Chicago, Ill.

WEBER, M. 1949 The Methodology of the Social Sciences, The Free Press of Glencoe, New York, NY.

WINCH,P. 1990 The Idea of a Social Science and its Relation to Philosophy (second edition), Routledge and Kegan Paul, London.

ZIMMERMAN,D. 1971 'The practicalities of rule use,' in J.Douglas (ed)

Understanding Everyday Life, Routledge, London. 